\title{
Investigation of Membrane-Based Total Heat Exchangers with Different Structures and Materials
}

\author{
Ting-Shu Zhong ${ }^{1}$, Zhen-Xing Li ${ }^{1}$ and Li-Zhi Zhang ${ }^{1,2, *}$ \\ ${ }^{1}$ Key Laboratory of Enhanced Heat Transfer and Energy Conservation of Education Ministry, School of \\ Chemistry and Chemical Engineering, South China University of Technology, Guangzhou 510640, China \\ ${ }^{2}$ State Key Laboratory of Subtropical Building Science, South China University of Technology, Guangzhou \\ 510640, China
}

\begin{abstract}
Membrane-based total heat exchangers are devices to recover both sensible heat and latent heat from the exhaust air. The performances of exchangers assembled with different structures and membranes vary dramatically. To investigate performances, five modules are fabricated for comparison. A test rig is built to measure the performance of these total heat exchangers. The heat and moisture transfer in the cores are studied simultaneously. These cores can be divided into two categories: with different structures and with different membranes. For the first category, parallel-plates, plate-fins and cross-corrugated structures are used. For the second category, three kinds of membranes, i.e. one-step hand-made CA membrane, hydrophobic-hydrophilic composite membrane and machine-made CA membrane are used. The heat and mass transfer coefficients, sensible cooling and latent effectiveness are obtained through experimental measurements. The experimental results show that the cross-corrugated ducts can enhance heat and mass transfer effectively. And the one-step hand-made CA membrane has the lowest resistance in heat and moisture transfer.
\end{abstract}

Keywords: Total heat exchanger, core structure, membrane materials, energy recovery, comparison.

\section{INTRODUCTION}

Southern China and other Southeast Asia countries have a long summer season with a daily average temperature of $30^{\circ} \mathrm{C}$, and humidity ratio above $0.020 \mathrm{~kg} / \mathrm{kg}$. Air-conditioning in such hot and humid environments is essential for daily human activities. The energy consumption of air conditioning system is up to $50 \%-60 \%$ among the commercial construction energy consumptions, and energy used to cool and dehumidify the ventilation air ranges from $20 \%-40 \%$ of the energy consumption for air conditioning $[1,2]$. The percentage will surely be increasing with economic development. It is well known that energy recovery devices could save a large part of energy since heat and humidity would be recovered from the exhaust stream in winter, and excess heat and moisture would be transferred to the exhaust in summer. Typical energy recovery devices include metal heat exchanger, heat pipe exchanger and rotary exchanger. Through heat transfer, conduction, radiation, etc., metal heat exchanger and heat pipe exchanger can recover the energy while air streams flow between both sides. Since the energy recovery capacity is limited for they can just recover the sensible heat, it is not quite suitable to fulfill this task. Theoretically, rotary wheels should be more suitable for this task since they can recover both sensible heat and latent heat, which are

*Address correspondence to this author at the State Key Laboratory of Subtropical Building Science, South China University of Technology, Guangzhou 510640, China; Tel/fax: 86-20-87114264;

E-mail: Izzhang@scut.edu.cn the so-called total heat exchangers [3]. But in fact, rotary exchangers have a moving part. The crosscontamination between fresh air and exhaust air is hardly avoidable. This shortage greatly restricts their applications.

For these reasons, membrane-based total heat exchangers have caught much attention. The benefits of such equipment are: stationary, compact, no crosscontamination and easy to construct, etc. $[4,5]$. The devices are just like an air-to-air parallel plate sensible heat exchangers. But in place of traditional metal heat exchange plates, many kinds of thin membranes, which can transfer both heat and moisture simultaneously, are used as the transfer media and fabricated into different structures [6].

Internationally, many scholars have done a lot of researches about total heat exchangers. The literature review found that though the heat and mass transfer [716] in traditional chevron plate heat exchangers have been investigated by various investigators, information on membrane types and structures are rare, especially for cross-corrugated triangular ducts. This study is focused on finding the most suitable membrane materials and structures for energy recovery. For comparison, in this study, five different cores were fabricated to test their performances. They can be divided into two categories. One is built with three different structures, parallel-plate, plate-fin and crosscorrugated. The other is constructed with different membranes, one-step hand-made cellulose acetate 
membrane, hydrophobic-hydrophilic composite membrane, and machine-made CA membrane.

\section{HEAT AND MOISTURE TRANSFER}

For a total heat exchanger, the heat and moisture transfer efficiency is an important criterion to evaluate its performances.

The sensible effectiveness is calculated by

$\varepsilon_{\mathrm{s}}=\frac{m_{\mathrm{f}}\left(T_{\mathrm{fi}}-T_{\mathrm{fo}}\right)+m_{\mathrm{e}}\left(T_{\mathrm{eo}}-T_{\mathrm{ei}}\right)}{2 m_{\min }\left(T_{\mathrm{fi}}-T_{\mathrm{ei}}\right)}$

where $m_{\mathrm{f}}$ and $m_{\mathrm{e}}$ are the mass flow rates of fresh air and exhaust air, $\mathrm{kg} / \mathrm{s} . m_{\min }$ is the smaller one between $m_{\mathrm{f}}$ and $m_{\mathrm{e}}$. $\mathrm{T}$ is the air temperature, the subscripts ' $\mathrm{f}, \mathrm{e}$, i, o' mean the fresh air, exhaust air, inlet and outlet, respectively. During the experiment, the flow rates of fresh air and exhaust air are equal, so equation (1) can be simplified as

$\varepsilon_{\mathrm{s}}=\frac{\left(T_{\mathrm{fi}}-T_{\mathrm{fo}}\right)+\left(T_{\mathrm{eo}}-T_{\mathrm{ei}}\right)}{2\left(T_{\mathrm{fi}}-T_{\mathrm{ei}}\right)}$

Identically, the latent effectiveness is calculated for simplify as

$\varepsilon_{\mathrm{L}}=\frac{\left(\omega_{\mathrm{fi}}-\omega_{\mathrm{fo}}\right)+\left(\omega_{\mathrm{eo}}-\omega_{\mathrm{ei}}\right)}{2\left(\omega_{\mathrm{fi}}-\omega_{\mathrm{ei}}\right)}$

where $\omega$ stands for humidity ratio in the wind tunnels, $\mathrm{kg} / \mathrm{kg}$.

The Nusselt number is defined as

$N u=\frac{h_{\mathrm{f}} D_{\mathrm{h}}}{\lambda_{\mathrm{a}}}$

where $h_{\mathrm{f}}$ is the convective heat transfer coefficient in fresh air side, $D_{\mathrm{h}}$ is the hydraulic diameter of the core channel, $\lambda_{\mathrm{a}}$ is the thermal conductivity in air, $\mathrm{kW} \mathrm{m}^{-1}$ $\mathrm{K}^{-1}$.

The Sherwood number is defined as

$$
S h=\frac{k_{\mathrm{f}} D_{\mathrm{h}}}{D_{\text {va }}}
$$

where $k_{f}$ is the convective mass transfer coefficient, $\mathrm{m} / \mathrm{s} ; D_{\mathrm{va}}$ is the moisture diffusivity in dry air, $\mathrm{m}^{2} / \mathrm{s}$.

The hydraulic diameter of the exchanger channel is defined as
$D_{\mathrm{h}}=\frac{4 V_{\mathrm{cyc}}}{A_{\mathrm{cyc}}}$

The Reynolds number is defined as

$\operatorname{Re}=\frac{D_{\mathrm{h}} u \rho_{\mathrm{a}}}{\mu_{\mathrm{a}}}$

where $\rho_{\mathrm{a}}$ is air density, $\mathrm{kg} / \mathrm{m}^{3} ; \mu_{\mathrm{a}}$ is the air viscosity, $\mathrm{Pa} \cdot \mathrm{s} ; \mathrm{u}$ is the air velocity, $\mathrm{m} / \mathrm{s}$.

With the measured inlet and outlet mean variables, the heat transfer coefficient can be calculated by

$h_{\mathrm{tot}}=\frac{c_{\mathrm{pa}} \rho_{\mathrm{a}} V_{\mathrm{a}}\left(T_{\mathrm{fi}}-T_{\mathrm{fo}}\right)}{A_{\mathrm{tot}} \Delta T_{\mathrm{m}}}$

and

$\Delta T_{\mathrm{m}}=\psi \frac{\left(T_{\mathrm{fi}}-T_{\mathrm{eo}}\right)-\left(T_{\mathrm{fo}}-T_{\mathrm{ei}}\right)}{\ln \frac{T_{\mathrm{fi}}-T_{\mathrm{eo}}}{T_{\mathrm{fo}}-T_{\mathrm{ei}}}}$

where $c_{\mathrm{pa}}$ is specific heat of air, $\rho_{\mathrm{a}}$ is density of the air, $\mathrm{kg} / \mathrm{m}^{3} ; V_{\mathrm{a}}$ is the air flow rate of fresh air or exhaust air, $\mathrm{m}^{3} / \mathrm{s} ; A_{\text {tot }}$ is the total surface area of membrane, $\mathrm{m}^{2}$; $\Delta T_{\mathrm{m}}$ is the log mean temperature difference. $\psi$ is a correction factor for cross flow, and it can be find from [17]. And $h_{f}$ can be derived from

$\frac{1}{h_{\mathrm{tot}}}=\frac{1}{h_{\mathrm{f}}}+\frac{\delta}{\lambda_{\mathrm{m}}}+\frac{1}{h_{\mathrm{e}}}$

where $\delta$ is the thickness of membrane, $\mathrm{m} ; \lambda_{\mathrm{m}}$ is thermal conductivity of the membrane, $\mathrm{kW} \cdot \mathrm{m}^{-1} \cdot \mathrm{K}^{-1} ; h_{\mathrm{e}}$ is the convective mass transfer coefficient in exhaust air side, and nearly equals to $h_{\mathrm{f}}, \mathrm{kW} \cdot \mathrm{m}^{-2} \cdot \mathrm{K}^{-1}$.

The total number transfer unit of heat transfer is defined as

$N T U_{s}=\frac{A_{\mathrm{tot}} h_{\mathrm{tot}}}{\rho_{\mathrm{a}} V_{\mathrm{a}} c_{\mathrm{pa}}}$

The mass transfer coefficient can be calculated by

$k_{\mathrm{tot}}=\frac{\rho_{\mathrm{a}} V_{\mathrm{a}}\left(\omega_{\mathrm{fi}}-\omega_{\mathrm{fo}}\right)}{A_{\mathrm{tot}} \Delta \omega_{\mathrm{m}}}$

and

$\Delta \omega_{\mathrm{m}}=\psi \frac{\left(\omega_{\mathrm{fi}}-\omega_{\mathrm{eo}}\right)-\left(\omega_{\mathrm{fo}}-\omega_{\mathrm{ei}}\right)}{\ln \frac{\omega_{\mathrm{fi}}-\omega_{\mathrm{eo}}}{\omega_{\mathrm{fo}}-\omega_{\mathrm{ei}}}}$ 
where $\Delta \omega_{\mathrm{m}}$ is the log mean humidity difference, and $k_{\mathrm{f}}$ can be derived from

$\frac{1}{k_{\mathrm{tot}}}=\frac{1}{k_{\mathrm{f}}}+\frac{\delta}{D_{\mathrm{vm}}}+\frac{1}{k_{\mathrm{e}}}$

where $D_{\mathrm{vm}}$ can be measured using the field and laboratory emission cell (FLEC). The detail process has been introduced in $[18,19] . k_{\mathrm{e}}$ is the convective mass transfer coefficient in exhaust air side, and nearly equals to $k_{\mathrm{f}}, \mathrm{m} / \mathrm{s}$.

The total number transfer unit of mass transfer is defined as

$$
N T U_{L}=\frac{A_{\mathrm{tot}} k_{\mathrm{tot}}}{\rho_{\mathrm{a}} V_{\mathrm{a}}}
$$

\section{EXPERIMENTAL WORK}

\subsection{Test System}

A test rig, as shown in Figure 1, has been set up to measure the core performance. The test rig consists of blowers, wind tunnels, heaters, humidifiers, nozzles and total heat exchanger core. The converging wind tunnels produce steady, homogeneous, fully developed airs. Air in one tunnel is adjusted to imitate cool dry fresh air, and air in the other tunnel to imitate hot wet exhaust air. Before entering the cores, the air temperature and humidity can be adjusted to the set points by controlling the heating power and stream generation currents. Temperature and humidity sensors are inserted into the test section to measure the states of inlet and outlet air. The whole test rig is constructed in a constant temperature and constant humidity room, so the inlet air temperature and humidity can be well controlled during the experiment.

In order to test the core performances under different air conditions, various air state conditions are used. According to the JIS B 8628 standards (China), during the experiment, the operation conditions can be changed by adjusting the air flow rates, inlet air temperature and inlet air humidity. Core performances change with the varying parameters. The test

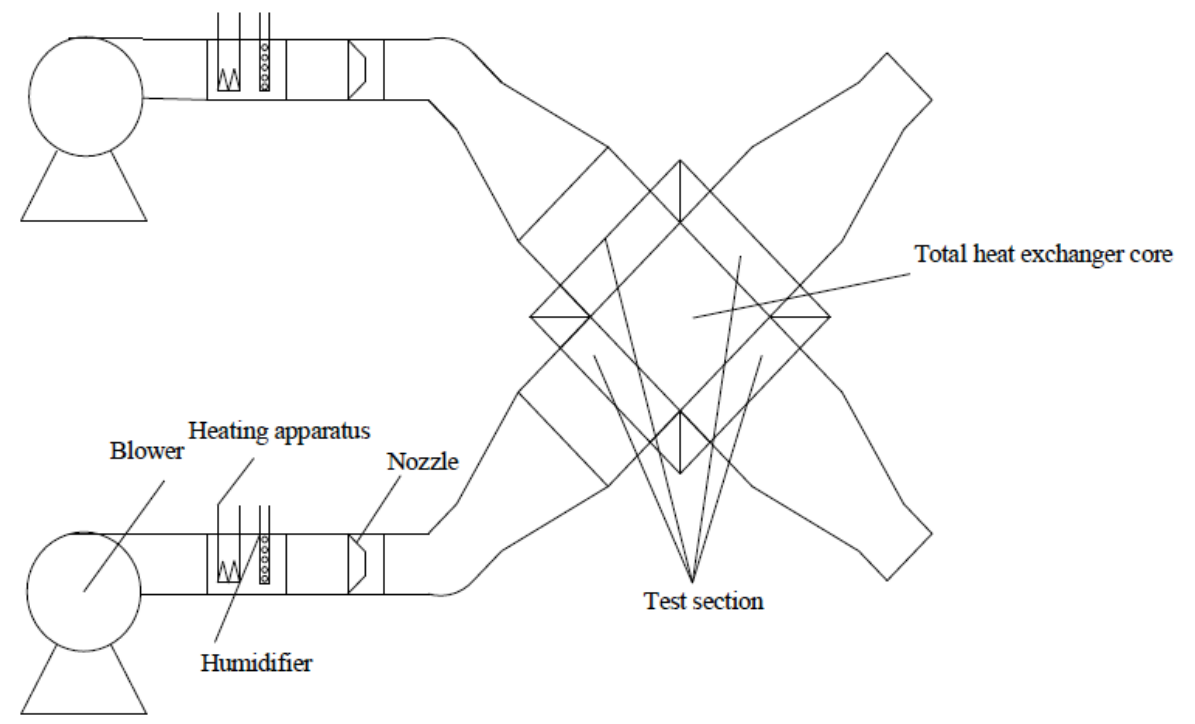

Figure 1: Schematic of the experimental setup.

Table 1: Detailed Experimental Operation Conditions

\begin{tabular}{|c|c|c|c|c|c|c|}
\hline \multirow{2}{*}{$\begin{array}{c}\text { Operation } \\
\text { conditions }\end{array}$} & $\begin{array}{c}\text { Air flow rates } \\
\left(\mathbf{m}^{3} / \mathbf{h}\right)\end{array}$ & $\begin{array}{c}\text { Temperature } \\
\left({ }^{\circ} \mathbf{C}\right)\end{array}$ & $\begin{array}{c}\text { Relative } \\
\text { humidity }(\%)\end{array}$ & $\begin{array}{c}\text { Air flow rates } \\
\left(\mathbf{m}^{3} / \mathbf{h}\right)\end{array}$ & $\begin{array}{c}\text { Temperature } \\
\left({ }^{\circ} \mathbf{C}\right)\end{array}$ & $\begin{array}{c}\text { Relative } \\
\text { humidity }(\%)\end{array}$ \\
\hline \hline $\begin{array}{c}\text { Varying inlet air flow } \\
\text { rates }\end{array}$ & $100-200$ & $35 \pm 1$ & $70 \pm 2$ & $100-200$ & $27 \pm 1$ & $50 \pm 2$ \\
\hline $\begin{array}{c}\text { Varying inlet air } \\
\text { temperature }\end{array}$ & 150 & $(30 \sim 40) \pm 1$ & $65 \pm 2$ & 150 & $27 \pm 1$ & $50 \pm 2$ \\
\hline $\begin{array}{c}\text { Varying inlet air } \\
\text { humidity }\end{array}$ & 150 & $35 \pm 1$ & $(45 \sim 75) \pm 2$ & 150 & $27 \pm 1$ & $50 \pm 2$ \\
\hline
\end{tabular}


Table 2: Physical Properties of Total Heat Exchanger Cores with Different Structures

\begin{tabular}{|c|c|c|c|c|c|}
\hline & & & Cross-corrugated & Plate-fin & Parallel-plate \\
\hline Name of properties & Symbol & Unit & Model A & Model B & Model C \\
\hline Module dimensions & $x_{\mathrm{F}} \times y_{\mathrm{F}} \times z_{\mathrm{F}}$ & $\mathrm{mm}^{3}$ & $182 \times 182 \times 462$ & $182 \times 182 \times 462$ & $182 \times 182 \times 462$ \\
\hline Number of channels & - & - & 31 & 126 & 90 \\
\hline Channel height & - & $\mathrm{mm}$ & 7.0 & 1.8 & 2.5 \\
\hline Aspect ratio & - & - & 0.5 & 0.36 & 0.03 \\
\hline Membrane thickness & $\delta$ & $\mathrm{mm}$ & 75 & 75 & 75 \\
\hline Moisture diffusivity in air & $D_{\text {va }}$ & $\mathrm{m}^{2} / \mathrm{s}$ & $2.82 \times 10^{-5}$ & $2.82 \times 10^{-5}$ & $2.82 \times 10^{-5}$ \\
\hline Effective moisture diffusivity in membrane & $D_{\mathrm{vm}}$ & $\mathrm{m}^{2} / \mathrm{s}$ & $3.77 \times 10^{-6}$ & $3.77 \times 10^{-6}$ & $3.77 \times 10^{-6}$ \\
\hline Thermal conductivity of membrane & $\lambda_{\mathrm{m}}$ & $\mathrm{W} /(\mathrm{m} \cdot \mathrm{K})$ & 0.127 & 0.127 & 0.127 \\
\hline Membrane area & $A$ & $\mathrm{~m}^{2}$ & 3.04 & 8.53 & 6.03 \\
\hline
\end{tabular}

conditions are called varying inlet air rate condition, varying inlet temperature condition and varying inlet humidity condition. The details of operational conditions are shown in Table 1.

\subsection{Total Heat Exchanger Cores}

\subsubsection{Cores with Different Structures}

The machine-made CA membrane is used as the material to form three cores with different duct structures, parallel-plates, plate-fins, and crosscorrugated. This membrane is very thin and soft. To form the specific structures, some plastic rods are used to support the membrane. The physical properties of the membrane and the cores' duct structures are shown in Table 2.

For each core, neighboring channels are in crossflow, which guarantees the same flow pattern for both fluids. Parallel-plate channel and plate-fin channel are simple and common structures for heat and moisture recovery. The schematic of parallel-plate channel has been shown in Figure $\mathbf{2 a}$, and each channel is rectangular. The plate-fin channel is shown in Figure $\mathbf{2 b}$, and the channel is triangular. Cross-corrugated triangular channel is a novel structure for compact total heat exchanger. The schematic is shown in Figure 2c. The flat membrane sheets are corrugated to form a series of parallel equilateral triangular ducts, whose apex angles are 90 degrees.

\subsubsection{Cores with Novel Membranes}

Membrane properties, such as moisture diffusivity in membrane, membrane thickness, microstructure, and the compositions, etc. are important factors which will affect the cores' performances. Here, hydrophobichydrophilic composite membrane, one-step hand-made asymmetric CA membrane, and a machine-made CA membrane (bought from a factory) are used to fabricate total heat exchanger cores, which are shown in Figure 3. And the SEM micrographs of three membranes are shown in Figure 4.

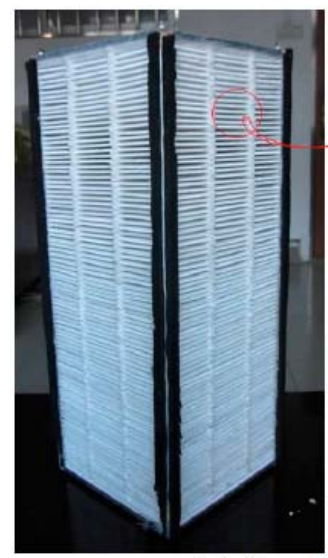

(a) Parallel-plate

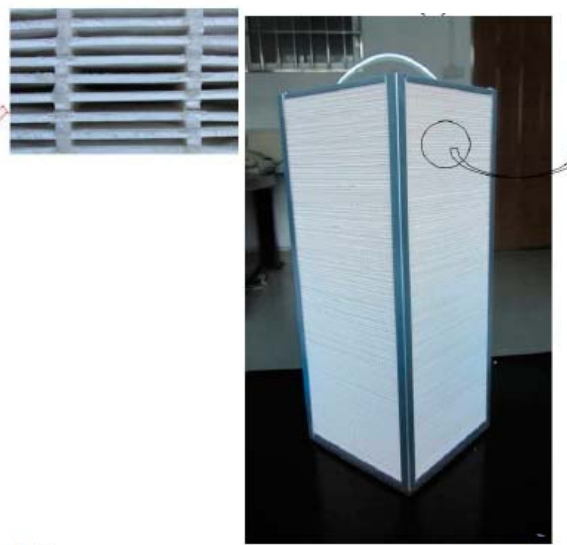

(b) Plate-fin

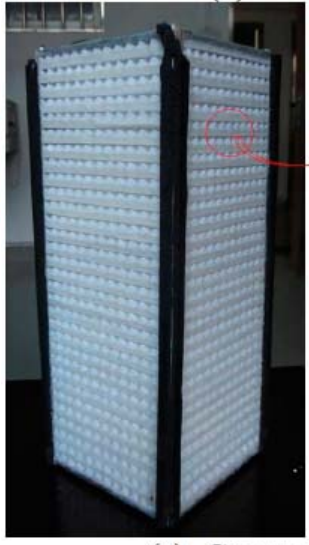

(c) Cross-corrugated

Figure 2: Total heat exchange cores with different structures. (Parallel-plate, Plate-fin and Cross-corrugated). 


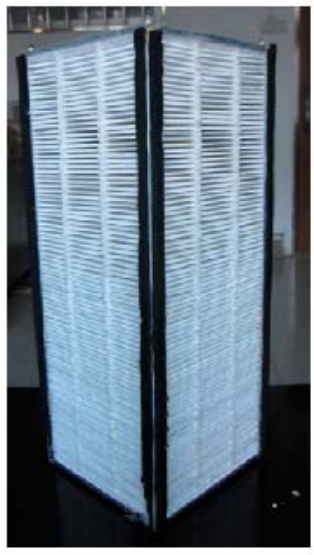

(a)

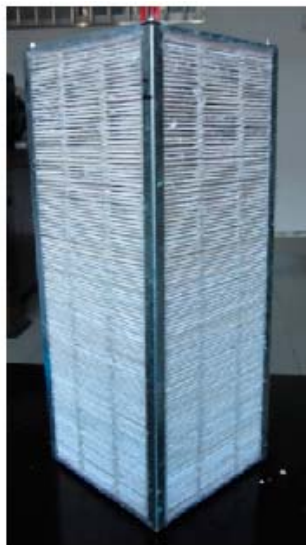

(b)

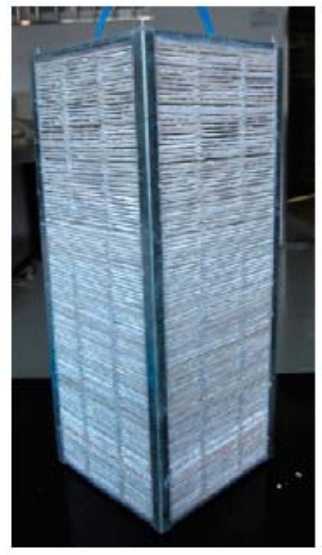

(c)

Figure 3: Total heat exchanger cores with different membranes. (a) Machine-made CA membrane; (b) One-step hand-made CA membrane; (c) Hydrophobic-hydrophilic composite membrane.

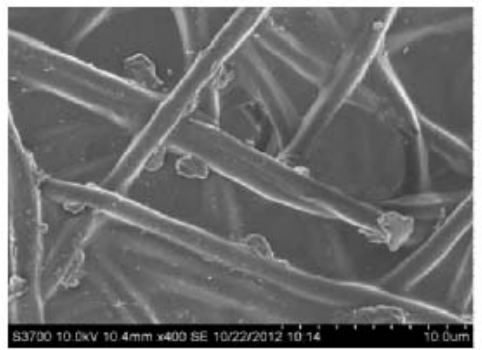

(a)Surface

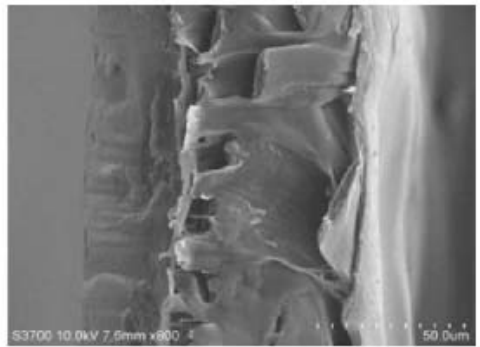

(b) Cross-section

Machine-made CA membrane

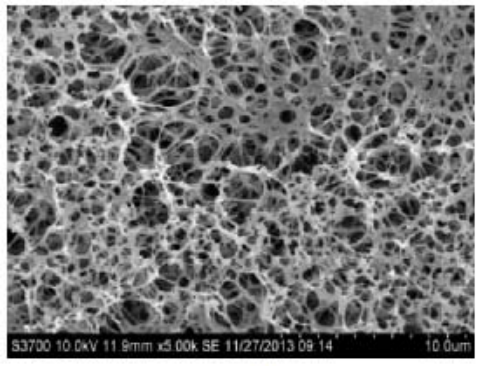

(a) Surface

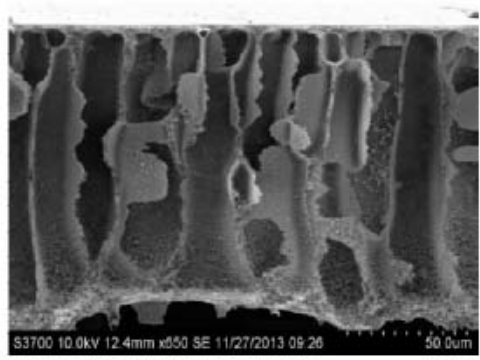

(b) Cross-section

One-step hand-made CA membrane

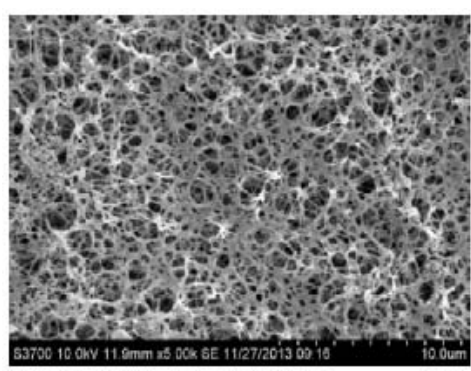

(a)Surface

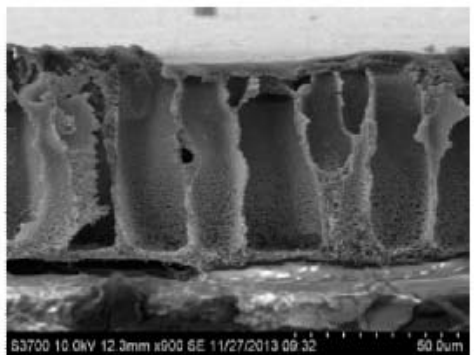

(b)Cross-section

Hydrophobic-hydrophilic composite membrane

Figure 4: SEM micrographs of three membranes (machine-made CA membrane, one-step hand-made asymmetric CA membrane and hydrophobic-hydrophilic composite membrane). 
The detailed fabrication process of hydrophobichydrophilic composite membrane has been introduced in $[19,20]$. This membrane presents a two-layer structure, i.e. skin layer (hydrophilic) and support layer (hydrophobic). The fabrication process contains two main parts. The first part is to prepare support layer. Homogenous hydrophobic polymer solution is coated onto the nonwoven cloth which is spread onto a clean glass plate. It is immersed into a coagulation bath. Support layer membrane is formed and peeled off from the glass. Then the membrane is put into a vacuum drying oven for about $1 \mathrm{~h}$ at $70^{\circ} \mathrm{C}$. After that, the support layer is prepared. The second part is to form skin layer. The skin layer is formed by coating the homogenous hydrophilic polymer solution onto the hydrophobic support layer. Then the membrane is put into a vacuum drying oven. After dried, the hydrophobic-hydrophilic composite membrane is well prepared. The thicknesses of skin layer and support layer can both be controlled by a casting knife, varying from dozens to hundreds of nanometers.

For asymmetric hand-made CA membrane, it can be made by one-step approach. The detailed fabrication process also has been introduced in [21, 22]. It is the so-called wet phase inversion method. The process is similar to the first part of fabricating hydrophobic-hydrophilic composite membrane. Homogenous solution, which is cooled down and debubbled, is coated onto the nonwoven. Membrane thickness is also controlled by a casting knife. After coated, the membrane is kept under the room temperature for another 2 minutes before it is immersed into a coagulation bath. The membrane is transferred from the coagulation bath to clean water for $24 \mathrm{~h}$ to remove the excess reagent when it is peeled off from the glass plate. Then the membrane is placed into a vacuum drying oven at $70^{\circ} \mathrm{C}$ for about $1 \mathrm{~h}$. After dried, the membrane is prepared. This membrane also contains a two-layer structure, skin layer and support layer. From this, the largest advantage for asymmetric $\mathrm{CA}$ membrane is the simpler fabrication.

The physical properties of these three novel membrane total heat exchanger cores are shown in Table 3.

\section{RESULTS AND DISCUSSION}

\subsection{Heat and Mass Transfer Coefficients}

Figure 5 shows the tested Nusselt and Sherwood numbers under different air flow rates for the total heat exchangers. The subscript $A, B, C, D$, and $E$ represent module $A, B, C, D$ and $E$ respectively. From module $A$, $\mathrm{B}$ and $\mathrm{C}$, it is easy to notice that the $\mathrm{Nu}$ and Sh for cross-corrugated core are increasing rapidly with the increasing air flow rates, but those for parallel-plates and plate-fins are change little. It can be seen that both $\mathrm{Nu}$ and Sh for module $\mathrm{A}$ are the largest. The Nusselt numbers for cross-corrugated ducts are 2.33-4.17 times larger than those for parallel-plates ducts, and 5.89-8.59 times larger than for plate-fins. For Sherwood numbers, the cross-corrugated ducts are 2.72-3.74 times of those of parallel-plates, and 7.19-11.25 times of plate-fins. Obviously, the cross-corrugated ducts is more suitable for energy recovery because it could enhance heat and mass transfer effectively.

For different membranes, it can be seen that the Nusselt and Sherwood numbers of module D are the largest among modules $\mathrm{C}, \mathrm{D}$ and $\mathrm{E}$. That means handmade CA membrane performs well in energy recovery, since module $D$ is built with hand-made $C A$ membranes. It is proved that the hand-made $\mathrm{CA}$

Table 3: Physical Properties of Total Heat Exchanger Cores with Different Membranes

\begin{tabular}{|c|c|c|c|c|}
\hline Properties & Units & Model C & Model D & Model E \\
\hline Membrane material & - & Machine-made CA & Hand-made CA & Hydrophobic-Hydrophilic \\
\hline Core structure & - & Parallel-plates & Parallel-plates & Parallel-plates \\
\hline$x_{\mathrm{F}} \times y_{\mathrm{F}} \times z_{\mathrm{F}}$ & $\mathrm{mm}^{3}$ & $182 \times 182 \times 462$ & $182 \times 182 \times 462$ & $182 \times 182 \times 462$ \\
\hline Channels number & - & 90 & 110 & 115 \\
\hline$\delta$ & $\mathrm{mm}$ & 75 & 75 & 75 \\
\hline$D_{\mathrm{va}}$ & $\mathrm{m}^{2} / \mathrm{s}$ & $2.82 \times 10^{-5}$ & $2.82 \times 10^{-5}$ & $2.82 \times 10^{-5}$ \\
\hline$D_{\mathrm{vm}}$ & $\mathrm{m}^{2} / \mathrm{s}$ & $3.77 \times 10^{-6}$ & $4.76 \times 10^{-6}$ & $4.06 \times 10^{-6}$ \\
\hline$\lambda_{\mathrm{m}}$ & $\mathrm{W} /(\mathrm{m} \cdot \mathrm{K})$ & 0.127 & 0.141 & 0.136 \\
\hline Membrane area & $m^{2}$ & 6.03 & 7.48 & 7.79 \\
\hline
\end{tabular}




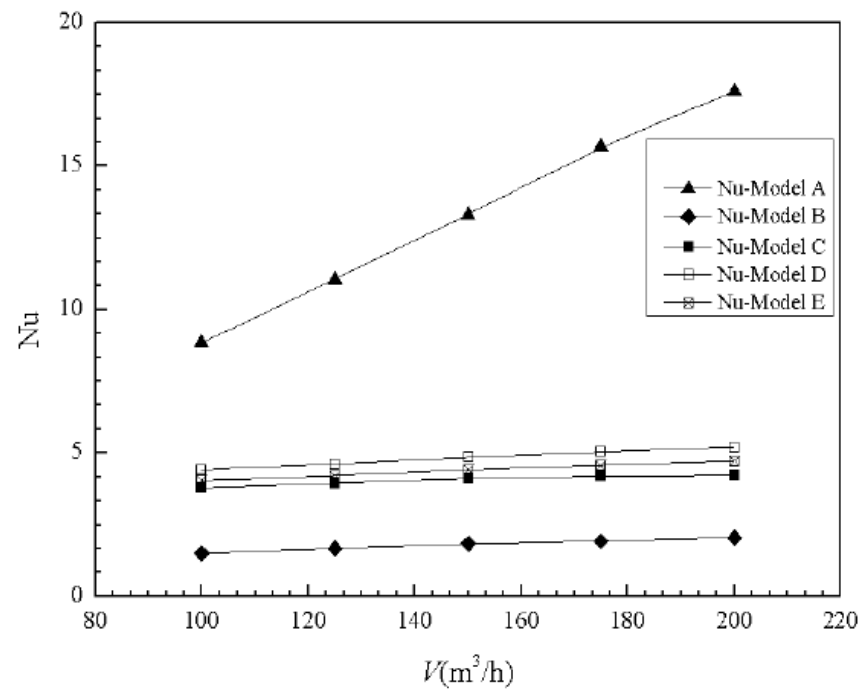

(a)Nusselt numbers

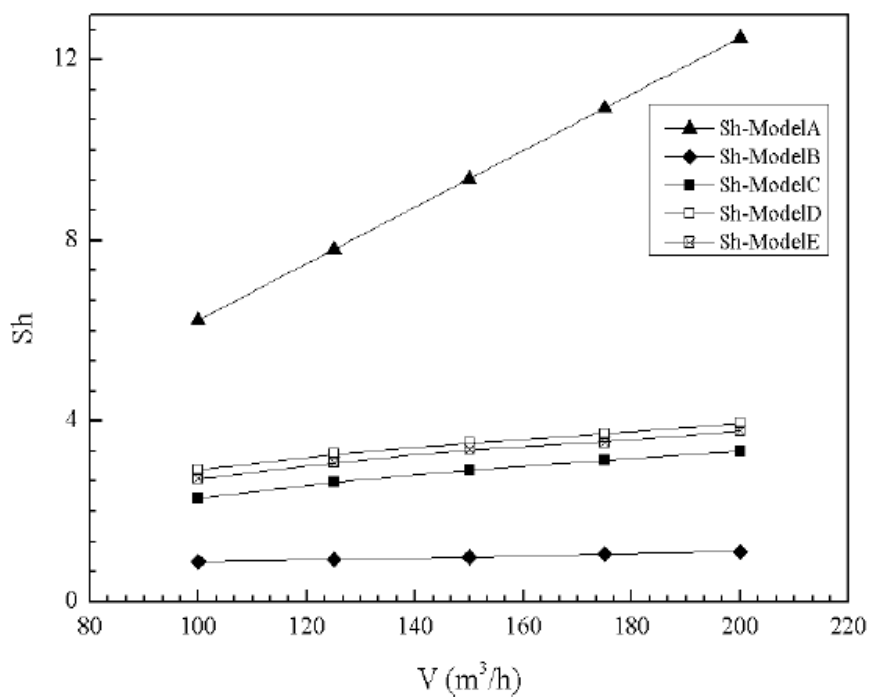

(b) Sherwood numbers

Figure 5: Nusselt and Sherwood numbers with varying air flow rates (fresh air inlet $35^{\circ} \mathrm{C}$ and $70 \% \mathrm{RH}$, exhaust air inlet $27^{\circ} \mathrm{C}$ and $50 \% \mathrm{RH})$.

membrane is the most suitable one for energy recovery among these three membranes because it has smaller resistance both in heat and moisture transfer.

\subsection{Sensible and Latent Effectiveness}

Figure 6 shows the experimental data of sensible and latent effectiveness. It can be seen from the graphs that both sensible effectiveness and latent effectiveness decline with the increasing inlet air flow rates. The reason is that, although heat and mass transfer coefficients increase with air flow rate, air flow rates increase too. The magnitudes of latter are larger than that of former. According to the calculation formulas, the final NTUs decrease. Therefore, the

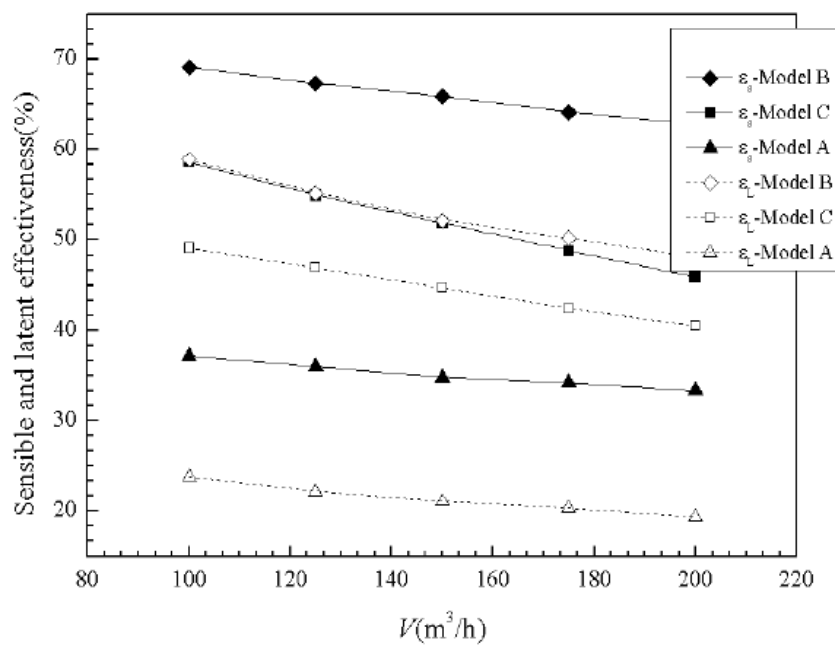

(a)Different structures efficiency of the exchanger decreases with the increasing air flow rates. The sensible effectiveness is always greater than latent effectiveness, because the mass transfer resistance is larger than the heat transfer resistance.

From Figure $6 a$, it can be seen that the module $B$ has the highest effectiveness, and module $C$ is the second. The effectiveness of module $A$ is the least. It seems that both the parallel-plate and plate-fin ducts perform better than the cross-corrugated duct in energy recovery. However, the total membrane areas packed are not the same for these three cores. The membrane areas of plate-fin and parallel-plate cores are two times larger than those of the cross-corrugated triangular

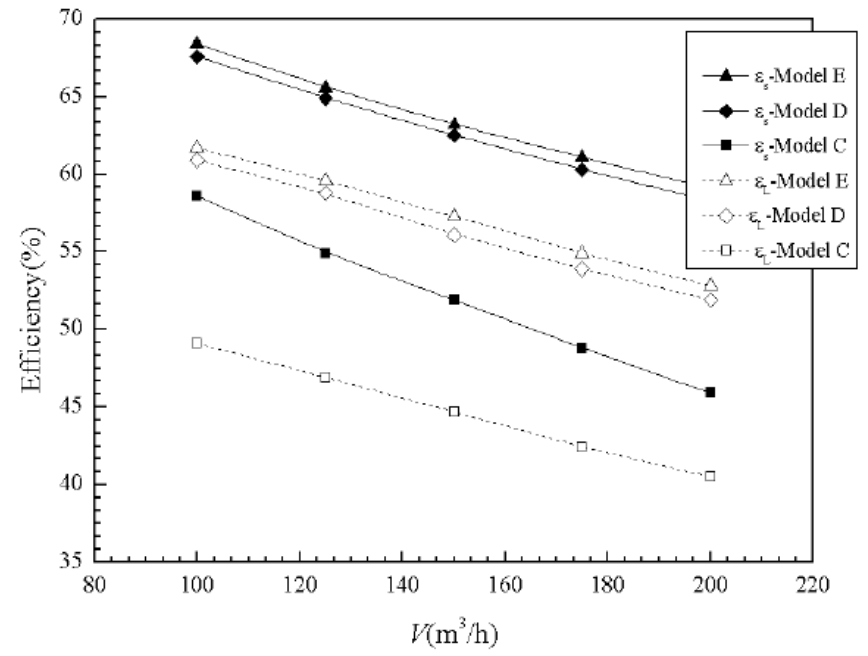

(b)Different membranes

Figure 6: Variations of sensible and latent effectiveness with air flow rates (fresh air inlet $35^{\circ} \mathrm{C}$ and $70 \%$, exhaust air inlet $27^{\circ} \mathrm{C}$ and $50 \%)$. 


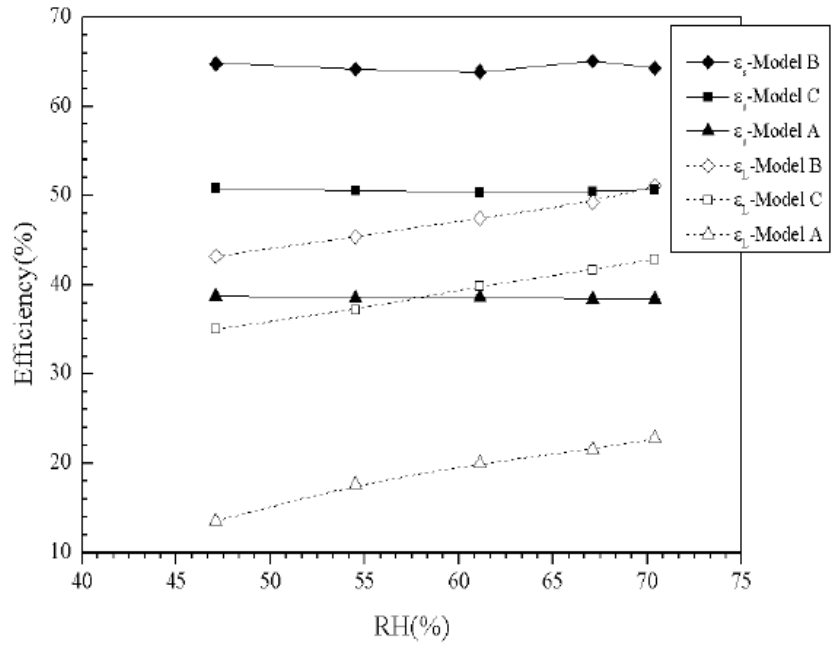

(a)Different structures

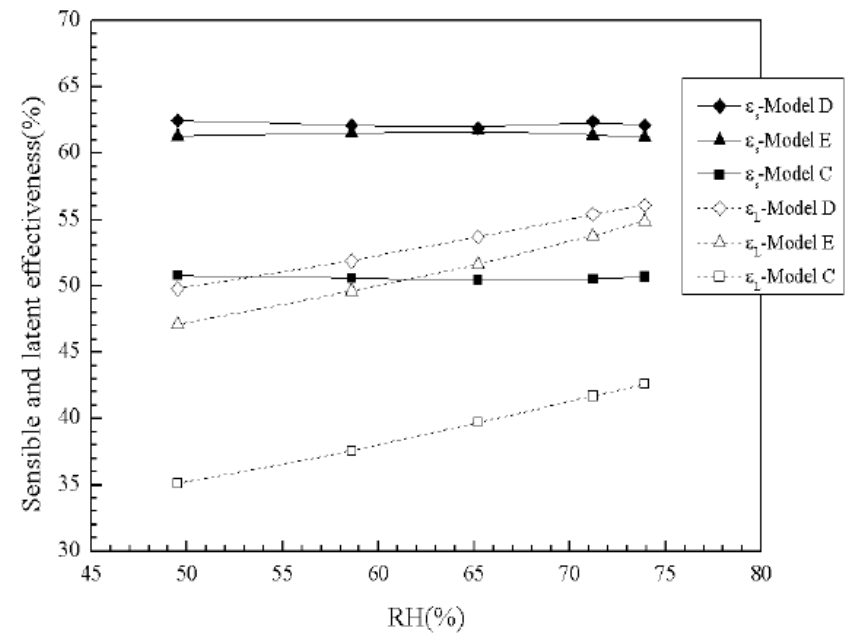

(b)Different membranes

Figure 7: Variations of sensible and latent effectiveness with inlet relative humidity (both inlet air rates are $150 \mathrm{~m}^{3} / \mathrm{h}$, fresh air inlet $35^{\circ} \mathrm{C}$, exhaust air inlet $27^{\circ} \mathrm{C}$ and $50 \%$ ).

ducts core. Therefore, if the effective membrane areas are equal, modules with cross-corrugated plates will have higher effectiveness.

Figure $\mathbf{6 b}$ shows the core performances with different membranes. It can be seen that both handmade CA membrane and hydrophobic-hydrophilic composite membrane play a good job in energy recovery. The effectiveness of module $E$ is a bit larger than that of module D. Considering its membrane area from Table 3, the effective membrane area is larger than that of module D. Owing to a larger packing area, module $E$ has a higher effectiveness than that of module D. From Figure 5, it can also be noticed that both $\mathrm{Nu}$ and Sh numbers of hand-made CA membrane are the largest. If the effective membrane area is equal,

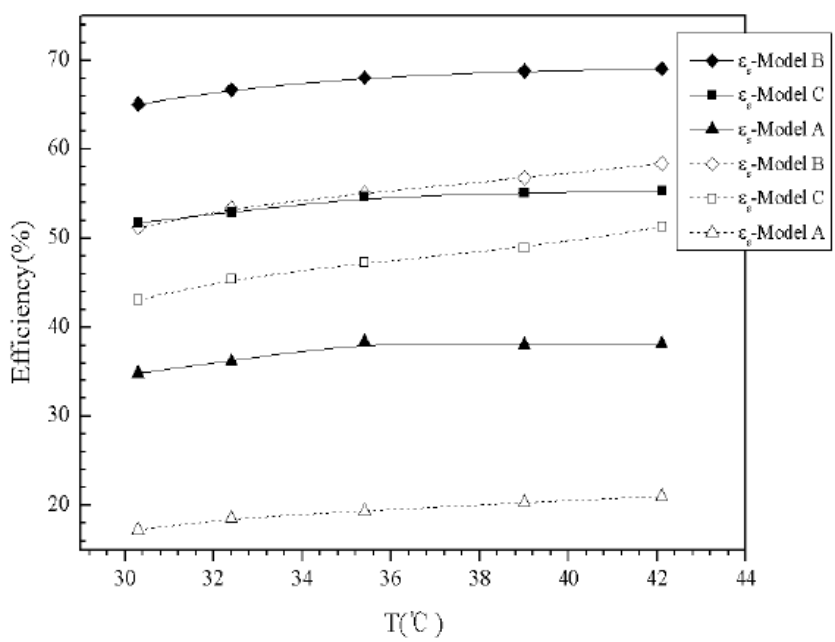

(a)Different structures module packed with hand-made CA membrane will have a higher effectiveness than that assembled with a hydrophobic-hydrophilic composite membrane.

Figure 7 shows the variations of sensible and latent effectiveness with inlet air relative humidity. Inlet humidity of exhaust air is kept stable (relative humidity $50 \%$ ). Inlet humidity of fresh air is changed linearly. The graph shows that the effect of humidity on sensible effectiveness is negligible. However for latent effectiveness, the effect is great. The higher the moisture difference is, the larger the mass transfer driving force will be.

Figure 8 shows the variations of sensible and latent effectiveness with inlet air temperatures. Inlet

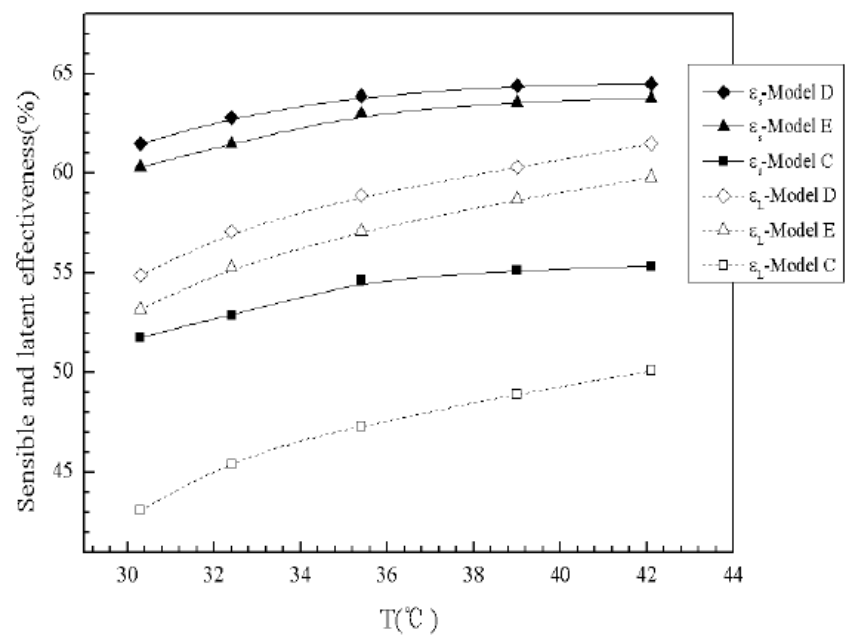

(b)Different membranes

Figure 8: Variations of sensible and latent effectiveness with inlet air temperatures (both inlet air rates are $150 \mathrm{~m}^{3} / \mathrm{h}$, fresh air inlet $70 \%$, exhaust air inlet $27^{\circ} \mathrm{C}$ and $50 \%$ ). 
temperature of exhaust air is kept stable $\left(27^{\circ} \mathrm{C}\right)$. Inlet temperature of fresh air is changed linearly. The graph shows that the sensible effectiveness is less sensitive to temperature variation than latent effectiveness. The reason is that membrane moisture resistance has a greater influence on total mass transfer resistance, while the effect of membrane thermal resistance on total heat resistance is negligible. When the inlet air temperature is increased, the inlet air humidity is increased, either. The driving force is larger at a higher inlet temperature.

\section{CONCLUSIONS}

(1) The air flow rates have a great impact on cores sensible and latent effectiveness. Both sensible effectiveness and latent effectiveness decline with the increasing air flow rates. The effect of inlet humidity on sensible effectiveness can be neglected, but for latent effectiveness, the higher the inlet humidity is, the larger the latent effectiveness will be. Under the varied temperature conditions, the sensible effectiveness is less sensitive to temperature variation than latent effectiveness.

(2) The cross-corrugated triangular ducts has the largest Nusselt and Sherwood numbers among the three structures (cross-corrugated triangular ducts, plate-fins and parallel-plates). If the effective membrane area is equal, modules built with cross-corrugated plates will obviously do the best job in energy recovery.

(3) The module packed with hand-made CA membrane has the best performance among the three different membranes (machine-made CA, hand-made CA and hydrophobic-hydrophilic composite membrane). It is proved that handmade CA membrane is more suitable for total heat recovery.

\section{ACKNOWLEDGEMENTS}

The Project is supported by Natural Science Foundation of China, No. 51161160562.

\section{APPENDIX}

$$
\begin{aligned}
& A_{\text {cyc }} \quad=\text { surface area of a flow cycle }\left(\mathrm{m}^{2}\right) \\
& A_{\mathrm{tot}} \quad=\text { total area of a core }\left(\mathrm{m}^{2}\right) \\
& c_{\mathrm{p}} \quad=\text { specific heat of fluid }\left(\mathrm{kJ} \quad \mathrm{kg}^{-1} \cdot \mathrm{K}^{-1}\right)
\end{aligned}
$$

$$
\begin{aligned}
& D_{\mathrm{h}} \quad=\quad \text { hydrodynamic diameter }(\mathrm{m}) \\
& D_{\mathrm{va}} \quad=\text { moisture diffusivity in dry air }\left(\mathrm{m}^{2} / \mathrm{s}\right) \\
& D_{\mathrm{vm}} \quad=\quad \text { effective moisture diffusivity in membrane } \\
& \left(\mathrm{m}^{2} / \mathrm{s}\right) \\
& h=\text { convective heat transfer coefficient } \\
& \left(\mathrm{kW} \cdot \mathrm{m}^{-2} \cdot \mathrm{K}^{-1}\right) \\
& k=\text { convective mass transfer coefficient }(\mathrm{m} / \mathrm{s}) \\
& \mathrm{m}=\text { mass flow rate }(\mathrm{kg} / \mathrm{s}) \\
& \mathrm{Nu} \quad=\quad \text { Nusselt number } \\
& \text { NTU }=\text { Number of transfer unit } \\
& \text { Sh }=\text { Sherwood number } \\
& \operatorname{Re} \quad=\text { Reynolds number } \\
& T=\text { temperature }(\mathrm{K}) \\
& u=\text { velocity }(\mathrm{m} / \mathrm{s}) \\
& V_{\mathrm{a}} \quad=\text { air flow rate }\left(\mathrm{m}^{3} / \mathrm{s}\right) \\
& V_{\text {cyc }}=\text { volume of a flow cycle }\left(\mathrm{m}^{3}\right)
\end{aligned}
$$

\section{Greek Letters}

$$
\begin{array}{ll}
\varepsilon & =\text { effectiveness } \\
\rho & =\text { density }\left(\mathrm{kg} / \mathrm{m}^{3}\right) \\
\lambda & =\text { thermal conductivity }\left(\mathrm{kW} \cdot \mathrm{m}^{-1} \cdot \mathrm{K}^{-1}\right) \\
\delta & =\text { thickness of the membrane }(\mathrm{m}) \\
\psi & =\text { correction factor } \\
\mu & =\text { viscosity }(\text { Pa.s }) \\
\omega & =\text { humidity ratio }(\mathrm{kg} / \mathrm{kg})
\end{array}
$$

\section{Subscripts}

$\begin{array}{ll}\mathrm{a} & =\text { air } \\ \text { cyc } & =\text { cyclic } \\ \mathrm{e} & =\text { exhaust air } \\ \mathrm{f} & =\text { fresh air } \\ \mathrm{i} & =\text { inlet } \\ \mathrm{L} & =\text { Latent heat }\end{array}$




$\begin{array}{ll}\mathrm{m} & =\text { mean, membrane } \\ \mathrm{O} & =\text { outlet } \\ \mathrm{S} & =\text { sensible heat } \\ \mathrm{T} & =\text { vapor } \\ \mathrm{v} & \text { REFERENCES }\end{array}$

[1] Li ZJ, Jiang Y. Analysis on cooling energy consumption of residential buildings in China's urban areas. Heating Ventilation and Air Conditioning 2009; 39(5): 82-8.

[2] Fu H, Gong YF, Yu XE, Li YD, Song WF. Effects of external wall shading on building's thermal environment and air conditioning energy consumption in hot summer and cold winter area. Architecture Technology 2012; 43(01): 67-70.

[3] Wu Z, Melnik RVN, Borup F. Model-based analysis and simulation of regenerative heat wheel. Energy Build 2006; 38: $502-14$

http://dx.doi.org/10.1016/j.enbuild.2005.08.009

[4] Kistler KR, Cussier EL. Membrane modules for building ventilation. Chemical Engineerging Research and Design 2002; 80: 53-64. http://dx.doi.org/10.1205/026387602753393367

[5] Zhang LZ, Jiang Y. Heat and mass transfer in a membranebased Enthalpy Recovery Ventilator. Journal of Membrane Science 1999; 163: 29-38. http://dx.doi.org/10.1016/S0376-7388(99)00150-7

[6] Zhang LZ. Progress on heat and moisture recovery with membranes: From fundamentals to engineering applications. Energy Conversion and Management 2012; 63: 173-95. http://dx.doi.org/10.1016/j.enconman.2011.11.033

[7] Freund S, Kabelac S. Investigation of local heat transfer coefficients in plate heat exchangers with temperature oscillation IR thermography and CFD. International Journal of Heat and Mass Transfer 2010; 53: 3764-81.

http://dx.doi.org/10.1016/j.jheatmasstransfer.2010.04.027

[8] Zhong K, Kang YM. Applicability of air-to-air heat recovery ventilators in China. Applied Thermal Engineering 2009; 29(5-6): 830-40. http://dx.doi.org/10.1016/i.applthermaleng.2008.04.003

[9] Liu ZY, Wu HY. Steady-state and transient investigation of the primary surface recuperator for microturbines. Heat Transfer Engineering 2013; 34: 875-86. http://dx.doi.org/10.1080/01457632.2012.746559

[10] Tsai YC, Liu FB, Shen PT. Investigations of the pressure drop and flow distribution in a chevron-type plate heat exchanger. International Communications in Heat and Mass Transfer 2009; 36: 574-8. http://dx.doi.org/10.1016/j.icheatmasstransfer.2009.03.013
[11] Zhang L, Che DF. Influence of corrugation profile on the thermalhydraulic performance of cross-corrugated plate. Numerical Heat Transfer, Part A: Applications 2011; 59: 26796.

http://dx.doi.org/10.1080/10407782.2011.540963

[12] Zhang LZ. Turbulent Three-Dimensional Air Flow and Heat Transfer in a Cross-Corrugated Triangular Duct. Journal of Heat Transfer 2005; 127(10): 1151. http://dx.doi.org/10.1115/1.2035110

[13] Zhang LZ. Convective mass transport in cross-corrugated membrane exchangers. Journal of Membrane Science 2005; 260(1-2): 75-83. http://dx.doi.org/10.1016/j.memsci.2005.03.029

[14] Tzanetakis N, Scott K, Taama WM, Jachuck RJJ. Mass transfer characteristics of corrugated surfaces, Applied Thermal Engineering. Applied Thermal Engineering 2004; 24: 1865-75. http://dx.doi.org/10.1016/j.applthermaleng.2003.12.007

[15] Zhang LZ. Numerical study of periodically fully developed flow and heat transfer in cross-corrugated triangular channels in transitional flow regime. Numerical Heat Transfer, Part A Applications 2005; 48(4): 387-405. http://dx.doi.org/10.1080/10407780590957314

[16] Ergin S, Ota A, Yamaguchi H. Numerical study of periodic turbulent flow through a corrugated duct. Numerical Heat Transfer, Part A: Applications 2001; 40: 139-56. http://dx.doi.org/10.1080/104077801750468462

[17] Xia Q, Chen CG. Unit operations of chemical engineering: TianJin University Press; 2007.

[18] Zhang LZ, Niu JL. Mass transfer of volatile organic compounds from painting material in a standard field and laboratory emission cell. International Journal of Heat and Mass Transfer 2003; 46(13): 2415-23.

http://dx.doi.org/10.1016/S0017-9310(03)00012-7

[19] Zhang LZ, Wang YY, Wang CL. Synthesis and characterization of a PVA/LiCl blend membrane for air dehumidification. Journal of Membrane Science 2008; 308(12): 198-206.

http://dx.doi.org/10.1016/j.memsci.2007.09.056

[20] Zhang LZ. Numerical study of heat and mass transfer in an enthalpy exchanger with a hydrophobic-hydrophilic composite membrane core. Numerical Heat Transfer, Part A: Applications 2007; 51(07): 697-714. http://dx.doi.org/10.1080/10407780600879048

[21] Zhang XR, Zhang LZ, Llu HM, Pei LX. One-step fabrication and analysis of an asymmetric cellulose acetate membrane for heat and moisture recovery. Journal of Membrane Science 2011; 366(1-2): 158-65. http://dx.doi.org/10.1016/j.memsci.2010.09.054

[22] Zhang XR, Zhang LZ, Pei LX. Sorption, permeation adn selective transport of moisture/VOCs through a CA membrane for total heat recovery. International Journal of Low-Carbon Technologies 2012; 0: 1-6. 